\title{
Investigation of interregional economic integration based on index analysis
}

\author{
Liudmila Borisova ${ }^{1}$ and Dina Borisova ${ }^{1 *}$ \\ ${ }^{1}$ Don State Technical University, sq. Gagarina, 1, Rostov-on-Don, 344010, Russia
}

\begin{abstract}
The paper suggests an approach based on the application of index analysis when studying the process of interregional economic integration. Interregional economic integration can be regarded as a multilateral process, covering various industrial and business ties, social and economic relations, arising between mesa economic entities - regions of the country. Economic interests of the entities of transregional ties are the backbone foundation of this process. The practical use of the index method for the analysis of the interregional commodity turnover as one of the main economic indicators that define the development of interregional economic integration, made it possible to study geographic structure of import and export of goods, evaluate and obtain new results characterizing interregional interaction of Rostov Region with regions of the Southern Federal District in dynamics for three large types of products: food products, non-food products, technical and industrial goods. In the course of study of trade and business ties of the region with other participants of the interregional integration the sectoral and geographical structures of import and export of goods, interdependence of economic-wide indicators and the degrees of the region's economic ties development, the problems of the efficiency of the existing sectoral structure of interregional commodity exchange were analyzed.
\end{abstract}

\section{Introduction}

Ensuring sustainable growth of the Russian economy is one of the most important problems of the contemporary social development. Solution of this problem is closely connected with enhancement of interregional economic integration which makes it possible to use the totality of resources of partner- regions to intensify their social and economic development.

Methods and means used for these purposes in practice for studying the processes of interregional economic integration, analysis and assessment of its present level do not always adequately reflect real conditions of functioning of the integrated regions. Therefore, the necessity for development of the well-known and working out new approaches and methods of investigating the processes of interregional integration, evaluating tools and methods for managerial decision-making, bring about the relevance of the subject under study.

\footnotetext{
*Corresponding author: borisovalv09@mail.ru
} 
The papers of national and foreign scientists are devoted to the problems of investigating the interregional economic integration. The analysis has shown that despite a wide range of object and subject for the analysis, the problems of assessing the current level and substantiating the directions for the development of the process of interregional economic integration remain insufficiently worked out [1-8].

In particular, the investigation in [2] is based on the application of the method of structural and functional analysis and has predominantly a descriptive character. And in [3] the existing knowledge is synthesized, and a conceptual framework for the analysis of interregional flows is developed, and the influence of the flows of ecosystem services on interregional stability is considered. A small number of papers [4-9] are devoted to the problems of quantitative assessment of interregional interaction and mathematical modeling of the process of interregional economic integration and require their further development.

Revealing the specific features and trends of interregional interaction, its strategic priorities should have a conceptual character. Investigation of these processes will make it possible to consider interregional relations not also as factors of social and economic development

This approach emphasizes that in the basis of interregional interaction there are regional interests which induce to build the system of economic interaction taking into account their own capabilities and strategic aims [10 - 13].

The two parties of interregional interaction reflect the objective character of the occurring processes, from one hand, the regions strive for economic cooperation, from the other hand, they strive for strengthening their competitive positions. This is how the relations of interregional cooperation and interaction with regions-partners are formed.

The Southern Federal District as a large social and economic system includes: Rostov Region, Krasnodar Territory, Astrakhan and Volgograd Regions, Adygea and the Republic of Kalmykia.

It was previously established that interregional integration is based on economic interest and is controlled by the system of social and economic regularities and rules-of-law. Any interregional ties are implemented through various kinds of activities in the following fields: innovative, investing, informational, resource, energy, production and technological cooperation, scientific and technical cooperation, financial interaction, mutual exchange of natural labor resources.

The level of effectiveness of interactions between different layers of the hierarchical structure of the economic system depends on the existing array of tools for managing such processes. When adjusting these relationships, it is necessary to strive for achieving an optimal balance of economic interests of all parties involved, to ensure consistency of actions focusing on the use of competitive advantages, coherency, and predictability of the expected results. Motivational interest in this case consists in mutual benefit from this kind of cooperation, in which integrational processes are effective in case of joint activity of the regions as a result of integration of their economies. The degree of development of energy and transport-logistic infrastructures decisively contributes to the intensity of interregional integration and stipulates the structure and volume of interregional turnover [14].

All the results of the interregional markets functioning can be divided into the following categories: - goods and services of a strategic nature, related to providing the country's security; - goods and services produced in the region from the standpoint of technological sustainability; - goods and services produced for consumption in the region within the framework of its economic space.

The existing criteria for ranking economic entities of the national economy are connected with assessment of the impact of their level of development on the processes of 
spatial development of the Russian economy. As a result, we can distinguish underdeveloped, depressed, and developed regions[15-17].

The underdeveloped regions are characterized by: insufficient intensity of economic processes, low living standards of the population and the economy structuredness, as a result of which they lag behind other regions in terms of production and technical level of development. About 25 constituent entities of the Russian Federation (including the entities of the Southern Federal District: Republic of Adygea, the Republic Kalmykia) now can be referred to these regions. The developed regions act as a kind of donors to the economy. Among them we can distinguish industrial, agrarian, and raw material regions. It is exactly these regions which act as poles of activity and economic growth, and entail other regions by the way of "diffusion of innovations". These are about 15 regions, that are the flagships of economic processes. Overcoming interregional imbalances and asymmetry, after all, requires constant search for adequate and effective tools for their elimination.

A spontaneous process (inherent in a market economy) of deepening social and economic differentiation of the regions acts as a barrier for further development of integrational interaction and decreases motivational incentives of the developing economic entities. The process of interregional redistribution of resources is limited enough and cannot, in full extent, provide support for lagging regions [18-19]. However, the problem of evening-out social and economic differences between the regions remains quite urgent.

Some conditions of effectiveness of interregional integration can be distinguished:

- demand for this form of interaction by the partner parties;

- unity of geoeconomics and geopolitical interests if the entities;

- relative equality of the levels of social and economic development;

-territorial proximity of the integration process participants.

As a result of the conducted qualitative analysis, the effects from the development of interregional integration were revealed, expressed in synergy and increase in target indicators of social and economic development of the national economy, such as the level of welfare of the population and the quality of life, the level of development of transport and logistics infrastructure, the level of the population employment, the level of investment attractiveness and business activity, the level of stable development of the regions, the level of ecologically favorable living conditions of the population in the regions. The availability of significant differences between the regions results in difficulty in the integration processes or to a decrease in their effect. In this case, economic relations are limited to the sphere of trade, episodic movement of trade, goods, or labor. Heterogeneity of the regions can lead to different results for each participant, to multidirectional consequences. The regional heterogeneity can lead to different results for each participant, to multidirectional consequences [20].

Territory proximity provides positive possibilities for interregional dynamics by means of reducing transport costs[21]. Such expenses are connected not only with growing tariffs but also with guarantees of performing economic obligations, breach of contract risks, growth of expenditures for administrative personnel etc.

Thus, interregional integration acts as a driver of social and economic development and promotes the growth of living standards of the population in the region and in the country, as a whole. The regions should form a common economic complex in reliance on the principle of complementarity. This is what will contribute to a widespread development of interregional integration.

The purpose of the investigation is to obtain new results when assessing interregional economic integration based on the application of index analysis. The object of investigation is regional social and economic systems of the Southern Federal District of the Russian Federation. 


\section{Methods}

The analysis of a priori information about the methods of investigation of interregional integration affirm the necessity to modernize the instrumental and mathematical apparatus of the quantitative assessment of the interregional integration, combining various methodological approaches into one whole system of approaches and methods, taking into account both quantitative and qualitative nature of informational and analytical basis for interregional economic interaction, including statistical methods of investigating the dynamics of the cross-border turnover in the regions of the Southern Federal District.

A comprehensive study of regional commodity markets and the analysis of their state make it possible to create prerequisites which promote an increase in the degree of the economic integration. For the analysis, it is reasonable to use the index method which allows to learn the geographical structure of import and export of goods, assess structural changes at the commodity markets, compare indicators, obtain new results characterizing the interregional interaction of the Rostov Region with partner regions of the Southern Federal District in real time. The study was carried out for three large types of products: food products (FP), non-food products (NFP), industrial and technical products (ITP). To solve the similar problems a summary index is used:

$$
I_{p q}=\frac{\sum p_{1} q_{1}}{\sum p_{0} q_{0}}
$$

where $p_{0} q_{0}$ and $p_{1} q_{1}$ are the calculated turnover in the base and current periods respectively, billion rubles.

In our studies the index method is applied to the analysis of statistical data on the turnover of the Rostov Region with the regions of the Southern Federal District published from 2013 to 2019. The basis for the investigation with application of the index method was statistical data characterizing interregional interaction of the Rostov Region with the regions of the Southern Federal District for three large types of products.

On the basis of these data, the calculated values of the composite indices were obtained, which incorporate different-sized elements: price and sales volume for the main product groups.

\section{Results}

As a result of the index analysis, the following calculated values of the considered indicators, presented in Table 1, were obtained, summary indices were determined which represent relative indicators characterizing the mean change in economic indicators consisting of incommensurable (different-sized) elements. In our case, these are prices and sales volumes in terms of different groups of goods. The calculation results for the indicators are summarized in Table 1.

The data obtained characterize the increase in commodity exchange in value terms in the Russian Federation and the Southern Federal District as a whole. When analyzing the dynamics of the indicator for the regions of the Southern Federal District, we can draw the following conclusions: there is a clear growth tendency with the Krasnodar territory and the Volgograd region. Periodic decreases $(2015,2017)$ and increases $(2014,2016,2019)$ of the turnover with the Astrakhan Region. This indicator decreased with Adygea in 2017, though before that time there was a growth tendency over the period of three years. As to Kalmykia, 
on the contrary, during the period of 2015-2016 the commodity exchange sharply decreased, and in 2017-2019 there was a sharp increase.

Table 1.The base indices of the turnover in the Rostov Region, in \% (2013 is a reference year)

\begin{tabular}{|l|c|c|c|c|c|c|c|}
\hline & 2013 & 2014 & 2015 & 2016 & 2017 & 2018 & 2019 \\
\hline RF & 100 & 109 & 112 & 131 & 146 & 157 & 163 \\
\hline SouthernFederalDistrict & 100 & 120 & 123 & 154 & 160 & 165 & 169 \\
\hline KrasnodarTerritory & 100 & 145 & 150 & 220 & 245 & 272 & 294 \\
\hline Astrakhan region & 100 & 120 & 99 & 77 & 128 & 148 & 156 \\
\hline Volgograd region & 100 & 95 & 103 & 108 & 127 & 134 & 139 \\
\hline Republic of Adygea & 100 & 99 & 139 & 170 & 145 & 155 & 153 \\
\hline Republic of Kalmykia & 100 & 142 & 76 & 61 & 117 & 129 & 142 \\
\hline
\end{tabular}

The available data are indicative of interregional disbalances in the commodity exchange of the Rostov Region with the regions of the Southern Federal District, which requires the search for effective tools to eliminate the existing differences.

Table 2. Initial and calculated data characterizing the indicators of import-export dynamics for the products between the Rostov Region and the Russian Federation.

\begin{tabular}{|c|c|c|c|c|c|c|}
\hline \multirow{2}{*}{ Year } & \multicolumn{3}{|c|}{ Volume, billion rubles } & \multicolumn{3}{c|}{ Indices, $\mathrm{I}_{\mathrm{pq}}$} \\
\cline { 2 - 7 } & Total for RF & Export & Import & $\begin{array}{c}\mathrm{I}_{\mathrm{pq}} \\
\text { total }\end{array}$ & $\begin{array}{c}\mathrm{I}_{\mathrm{pq}} \\
\text { Export }\end{array}$ & $\begin{array}{c}\mathrm{I}_{\mathrm{pq}} \\
\text { Import }\end{array}$ \\
\hline 2013 & 271197.30 & 124719.94 & 146477.36 & 100 & 100 & 100 \\
\hline 2014 & 294725.67 & 131283.74 & 163441.93 & 108.67 & 105.26 & 111.58 \\
\hline 2015 & 303055.88 & 130814.70 & 172241.18 & 111.74 & 104.88 & 117.58 \\
\hline 2016 & 353930.49 & 151073.52 & 202856.97 & 130.51 & 121.13 & 138.49 \\
\hline 2017 & 397224.68 & 173637.16 & 223587.52 & 146.47 & 139.22 & 152.64 \\
\hline 2018 & 426213.43 & 211427.28 & 214786.15 & 157.15 & 169.52 & 146.63 \\
\hline 2019 & 442254.64 & 226178.39 & 216076.25 & 163.07 & 181.34 & 147.51 \\
\hline
\end{tabular}

Table 3. Initial and calculated data characterizing the indicators of import-export dynamics for the products between the Rostov Region and the Southern Federal District.

\begin{tabular}{|c|c|c|c|c|c|c|}
\hline \multirow{2}{*}{ Year } & \multicolumn{3}{|c|}{ Volume, billion rubles } & \multicolumn{3}{c|}{ Indices, $\mathrm{I}_{\mathrm{pq}}$} \\
\cline { 2 - 7 } & $\begin{array}{c}\text { Total for } \\
\text { SFD }\end{array}$ & Export & Import & $\begin{array}{c}\mathrm{I}_{\mathrm{pq}} \\
\text { total }\end{array}$ & $\begin{array}{c}\mathrm{I}_{\mathrm{pq}} \\
\text { Export }\end{array}$ & $\begin{array}{c}\mathrm{I}_{\mathrm{pq}} \\
\text { Import }\end{array}$ \\
\hline 2013 & 47971.11 & 19226.38 & 28744 & 100 & 100 & 100 \\
\hline 2014 & 57519.75 & 25030.09 & 32489 & 119.9 & 130.18 & 113.02 \\
\hline 2015 & 58773.55 & 23076.19 & 35697 & 122.52 & 120.02 & 124.18 \\
\hline 2016 & 73893.21 & 32603.45 & 41289 & 154.03 & 169.57 & 143.64 \\
\hline 2017 & 76916.44 & 30400.05 & 46516 & 160.34 & 158.11 & 161.82 \\
\hline 2018 & 79324.23 & 33438.28 & 45885.95 & 165.36 & 173.19 & 159.63 \\
\hline 2019 & 81245.75 & 36827.49 & 44418.26 & 169.36 & 191.54 & 154.52 \\
\hline
\end{tabular}

In terms of application of the index analysis to characterize the interregional interactions, the turnover indices were calculated for the designated control points, which characterize 
import-export and the volume of products in value terms for Russia and the regions of the Southern Federal District.

The results of the index analysis of the turnover between the Rostov Region and the Southern Federal District are presented in Table 2 and Table 3, and between the Rostov Region and the partner regions of the Southern Federal District are presented below.

\section{Conclusion}

The analysis of the obtained statistical and calculated data made it possible to draw the following conclusions.

There has been observed an increase in turnover in 2017 in value terms with the Russian Federation, the Southern Federal District taken as a whole, and all the regions of the Southern Federal District, except for the Astrakhan Region and Adygea.

The import of goods to the Rostov Region from the Russian Federation, Southern Federal District, the Krasnodar Territory, the Volgograd Region has increased. Relating to the Astrakhan Region, it decreased in 2017, a significant decline in terms of volumes occurred with the imports from Kalmykia over the past 3 years.

Exports do not have any clear trend in growth or decline. In general, 2017 is characterized by an increase in the exported products to the Russian Federation, Astrakhan and Volgograd Regions, Kalmykia. There is a decrease in the exported products to the Southern Federal District, Krasnodar Territory, Adygea.

Export growth rates tend to decline. In 2017 there was an increase in the indicators for the export of goods.

Thus, social and economic differentiation of the regions in the Southern Federal District acts as a barrier for further development of the integration interaction of the Southern Federal District regions.

In consideration of the foregoing, it can be noted that in spite of the fact that there is an increase in the turnover in value terms, the growth rates of this indicator are decreasing from year to year. In terms of trade in products of all types import prevails over export, practically, with all the regions except Kalmykia. The most active exchange of commodities takes place between the Rostov Region and the Krasnodar Territory, the Volgograd Region is in the second place in the intensity of trade. The volume of interregional trade is in large part determined by the structure of production, investment policy, price level of raw material resources.

Thus, cross-border exchange of goods is an important tool of integrating convergence of the economic entities. The basis of this process is the presence of unrealized ways of interregional cooperation.

An increase in the efficiency of the processes of interregional integration is stipulated by the choice of partners in economic interaction, determination of the level of integrational ties between them, taking into account the possibility of complementarity of their economies, and provides a positive effect for the economies of the regions.

\section{References}

1. L. Bozhko, Energy Procedia 147, 397-401 (2018) doi.org/10.1016/j.egypro.2018.07.109

2. M. Schröter, T. Koellner, R. Alkemade, S. Arnhold, et al., Ecosystem Services 31 (B), 231-241 (2018) https://doi.org/10.1016/j.ecoser.2018.02.003 
3. E.N. Zakharova, E.E. Kardava, R.R. Avanesova, E.P. Avramenko, Regional Science Inquiry 8 (2), 45-54, (2016)

4. V.V. Prokhorova, E.N. Zakharova, Journal of Internet Banking and Commerce 21 (S4), 010, (2016)

5. E.N. Tishchenko, T.N. Sharypova, E.V. Zhilina, S.E. Cherkezov, Journal of Applied Economic Sciences 11 (5), 905-907, (2016)

6. E.N. Tishchenko, P.P. Belenkiy, T.N. Sharypova, O.V. Serpeninov, International Journal of Applied Engineering Research 11 (5), 3066-3074, (2016)

7. K.A. Butsik, E.N. Tishchenko, A mathematical model of a trusted download violator process «hardware thin client». CEUR Workshop Proceedings. YSIP2 2017 Proceedings of the 2nd Young Scientist's International Workshop on Trends in Information Processing, 32-37, (2017)

8. N.G. Vovchenko, M.B. Gontmacher, E.N. Tishchenko, T.V. Epifanova, European Research Studies Journal 20 (1), 36-48, (2017)

9. E.N. Tishchenko, E.V. Zhilina, T.N. Sharypova, G.N. Palyutina, Advances in Intelligent Systems and Computing 896, 694-701, (2019) doi.org/10.1007/978-3-03004164-9 91

10. D.V. Borisova, G.V. Gorelova, International scientific journal «Stable development of mountain areas», 11 (1), 65-7 - 0,7/0,4 p.s. (2019)

11. D.V. Borisova, Cognitive modelling of interregional economic integration in terms of fuzzy data. Cognitive modelling: Proceedings of the Seventh International forum on cognitive modelling (5 - 15 September 2019, Retimno, Greece, i. Crete). In 3 parts. Part 3. Cognitive modelling in science, culture, education: Proceedings of VII International conference «Cognitive modelling in science, culture, education. CMSCE2019» - Rostov-on-Don: Science and Education Fund, 243 - 252, (2019)

12. D.V. Borisova, G.V. Gorelova, N.D. Pankratova, Problems of interregional integration, cognitive modeling. 19th IFAC Conference on Technology, Culture and International Stability TECIS 2019Sozopol, Bulgaria, 26-28 September, 168-173, (2019) doi.org/10.1016/j.ifacol.2019.12.467

13. Y. Jiang, Trade, Foreign Direct Investment, and Development Strategies Chandos Asian Studies Series, 75-98, (2014) doi.org/10.1533/9781780634432.75

14. A. Landysh, T. Gadelshina, M. Vakhitova, Procedia Economics and Finance 24, 246250, (2015) doi.org/10.1016/S2212-5671(15)00655-3

15. T.F. Remington, Communist and Post-Communist Studies 48 (1), 1-13, (2015) doi.org/10.1016/j.postcomstud.2015.01.005

16. N. Serbulova, et al., IOP Conf. Ser.: Earth Environ. Sci. 403, 012127 (2019) doi.org/10.1088/1755-1315/403/1/012127

17. N. Serbulova, et al., E3S Web Conf., 210, 02005 (2020) doi.org/10.1051/e3sconf/202021002005

18. A. Alukhanyan, K. Barmuta, O. Panfilova, D. Borisova, IOP Conference Series: Earth and Environmental Science 403(1), 012044 (2019) doi.org/10.1088/17551315/403/1/012044

19. A.S. Orobinsky, A.A. Alukhanyan, R.A. Sychev, M.G. Kholina, European Research Studies Journal, 21, 333-349 (2018) 
20. 20) Kurdyukov, V., Kanurny, S. Conditions for the effective functioning of the system of internalization of economic damage from emissions in the territory. E3S Web of Conferences, 210, 13005 (2020) doi.org/10.1051/e3sconf/202021013005

21. 21) ZhukovaT., PanfilovaO., AvlasenkoI., AvlasenkoL. Peculiarities and development factors of modern agricultural engineering.E3S Web of Conferences, 175, 05028 (2020) doi.org/10.1051/e3sconf/202017505028 